\title{
Danish books recently published in the field of
}

American culture

Bertelsen \& Jacobsen, Eds., Kilder til Belysning af Cuba-krisen. (Sources concerning the Cuba crisis.) Copenhagen 1971.

Bjøl, Erling, Verdenshistorie siden 1945. (History of the World since 1945. Volumes 1 and 2. Volume 3 is under preparation. Contains an extensive analysis of United States domestic and foreign policy.). Copenhagen 1972 73.

Bøgh, Jens \& Skovmand, Steffen, Eds., Six American Novels: From New Deal to New Frontiers. Copenhagen 1972.

Dollerup, Preben, Den gode nabo med den store stok. Rapport. (The good neighbour with the big stick.) Copenhagen 1969.

Flato, Inga, Colonel House in Paris: A Study of American Policy at the Paris Peace Conference 1919. (Dissertation in History.) Aarhus 1972.

Henningsen, Svend, Atompolitik 19391945. (Atomic policy. 1939-1945.) Copenhagen 1971.

Henningsen, Svend, Det tyvende århundredes historie. Bind 2. 1930-1945. (History of the twentieth century. Volume 2. 1930-1945.) Copenhagen 1972.
Hvidt, Kristian, Flugten til Amerika eller Drivkræfter $i$ masseudvandringen fra Danmark 1868-1914. (Escape to America or Mass Emigration from Denmark 1868-1914.) Copenhagen 1971.

Krogh, Torben,.Den amerikanske trusel. (The American threat.) Copenhagen 1970.

Jessen, Nis, De nordamerikanske indianere. (The North American Indians.) Copenhagen 1970 .

Nørlyng, T. \& Nygaard, K., Ameeir og Australine. Copenhagen 1971.

Olsen, K. H., Nordamerikan. (North American.) Copenhagen 1971.

Thygesen, Erik, Ed,, Den amerikanske befrielsefront. (The American Liberation Front.) Copenhagen 1971.

Salto, Ivan, Ed., USA-almagt eller afmagt? (USA-all powerful or powerless?) Copenhagen 1969.

Wenzel, Jørgen, The Negro Revolt. Copenhagen 1971.

Nissen, H., Negrene-borgere uden rettigheder. (The Negroes-citize without rights.) Copenhagen 1972. 